\title{
Evaluating Chinese Mobile Health Apps for Ankylosing Spondylitis Management: Systematic App Search
}

\author{
Yuqing Song, MSN; Hong Chen, PhD \\ West China School of Nursing/West China Hospital, Sichuan University, Chengdu, China
}

Corresponding Author:

Hong Chen, $\mathrm{PhD}$

West China School of Nursing/West China Hospital

Sichuan University

No 37, Guoxuexiang

Wuhou District

Chengdu, 610041

China

Phone: 8618980601733

Email: 1366109878@qq.com

\section{Abstract}

Background: Patients with ankylosing spondylitis (AS), a chronic systematic inflammatory disease, require long-term treatment and management. Mobile health (mHealth) apps can deliver health services through mobile devices, facilitate long-term disease management, support patient-health care provider communication, and enable patients to engage in disease management. There are some apps targeted at patients with AS, but the feature and quality of these apps have not been systematically examined.

Objective: The aim of this study was to identify existing, publicly available Chinese mHealth apps for AS management and to evaluate their features and quality.

Methods: We systematically searched potential apps for AS management on the Apple and Huawei App Stores, using 4 search terms: ankylosing spondylitis, spondyloarthritis, rheumatic disease, and arthritis. Apps were included if they were in the Chinese language, targeted at patients with AS, could be downloaded and run on Android and/or iOS operating systems, and incorporated elements of disease management and/or patient education. We excluded apps that were not for patient use, not relevant to AS, or had not been updated since 2018. Apps that met the inclusion criteria were downloaded for final analysis. We formulated a list of app quality measures from and consistent with international guidelines for mHealth apps and AS management to evaluate the features and quality of the included app. The user version of the Mobile App Rating Scale (uMARS) was also used to rate the apps' quality.

Results: Of the 354 apps screened, 5 met the inclusion criteria and were included in our analysis. All apps were free, and most apps $(4 / 5,80 \%)$ had a privacy policy. Of the 5 apps, 1 (20\%) involved medical professionals in the development process, 2 (40\%) were developed by companies, and $2(40 \%)$ were developed by medical institutions. All apps provided educational information about AS. Around half of the apps had functions like a basic information record (ie, users can input gender, age, disease history, etc) $(n=3,60 \%)$, patient-health care provider (and patient-patient) communication $(n=2,40 \%)$, symptom tracking $(n=2,40 \%)$, and information sharing $(n=3,60 \%)$. Only $1(20 \%)$ app provided comprehensive functions that adhered to international guidelines for AS management and mHealth apps. The overall uMARS scores ranged from 2.7 to 4.2 ; only 1 app, with an overall uMARS score of 4.2, was considered as a high-quality app.

Conclusions: Most apps lacked comprehensive functions for AS management. One high-quality app provided comprehensive functions to help patients manage their conditions. This study assessed and summarized the features and quality of the apps but did not evaluate their efficacy. Future studies should evaluate the feasibility and efficacy of these apps. International guidelines and regulations for the design, development, validation, and implementation of mHealth apps are needed in the future. Meanwhile, health care providers, patients with AS, and app developers should collaborate to develop high-quality, evidence-based apps that take into account patients' needs and health care professionals' perspectives.

(JMIR Mhealth Uhealth 2021;9(7):e27234) doi: 10.2196/27234

\section{KEYWORDS}

ankylosing spondylitis; app; eHealth; mHealth; smartphone; mobile phone 


\section{Introduction}

Ankylosing spondylitis (AS) is a chronic systematic inflammatory disease that often causes structural impairment, functional disability, and impaired quality of life [1,2]. AS often affects young people at their most productive age (approximately 20-35 years) and has a lifelong impact on their life [1]. AS can interfere with work and schooling, and can impose substantial physical and social burdens on patients [3]. The guidelines of the European League Against Rheumatism (EULAR) recommend that $\mathrm{AS}$ requires long-term management, including pharmacological and nonpharmacological treatment, to control inflammation, prevent structural damage, and optimize function and quality of life [4]. The management of long-term conditions requires timely health care and treatment [5].

The traditional approach to AS management requires face-to-face rheumatology clinic appointments and treatment [6,7]. Patients with chronic diseases may have difficulty in attending regular rheumatology clinic appointments and obtaining timely treatment due to transportation difficulties, physical limitations, time constraints, and geographical barriers $[8,9]$. Moreover, China has a large population, with a broad geographical distribution of patients with AS; around $90 \%$ rheumatologists work at tertiary hospitals [10-12]. The barriers to receiving timely treatment and health care are much more prominent in China [11,13].

Mobile health (mHealth) has the potential to facilitate long-term disease management and deliver timely health care to hard-to-reach populations $[14,15]$. mHealth is defined as medical and public health practice supported by mobile devices, such as mobile phones, personal digital assistants, and other wireless devices $[16,17]$. mHealth apps can overcome barriers of time and geography to deliver health services through mobile devices and increase access to health care service [18]. Mobile apps offer a solution for patients with chronic diseases to monitor chronic conditions, support patient-health care provider communication, provide health advice, and enable patients to engage in disease management [10]. Many mHealth apps have been developed to help individuals with chronic diseases, such as asthma, rheumatoid arthritis, and inflammatory bowel disease, to manage their conditions [16,19-21]. Prior work has supported the usefulness of mHealth apps for enhancing disease management and improving clinical outcomes among patients with chronic diseases [15,22].

In China, 932 million people used smartphones to access the internet, and 3.59 million mobile apps were available as of 2020 [23]. Thus, mHealth interventions are increasingly accessible for Chinese people [10]. In the area of rheumatology, many studies revealed that mHealth apps for patients with rheumatoid arthritis have the potential to monitor their disease and support high-quality medical care [14,16,20,24]. Patients with AS may be one of the best target users of mHealth apps because AS affects young people (approximately 20-35 years) [10]. Young people are more likely to be acceptable to receiving an mHealth intervention $[25,26]$.

Limited published works in the literature have focused on mHealth apps for AS management in China [7,27]. Although the Smart System of Disease Management (SSDM) was used for AS management, the characteristics and functions of the SSDM have not been clearly described in the literature [7,27]. Our search of app stores found that there are some publicly available apps for AS management despite limited published works. However, there is little information to users on which apps provide evidence-based tools [20]. A previous review revealed that many apps are not supported by research, do not provide evidence-based therapies, and do not follow clinical guidelines [28]. Kwan et al [29] reviewed English-language apps for monitoring disease activity in patients with spondyloarthritis and found only 2 high-quality apps. However, the characteristics and functionalities of Chinese mHealth apps for AS management have not been systematically evaluated (eg, in terms of star rating, privacy policy, evidence-based content, and functionality).

The purpose of this study was to identify existing, publicly available apps targeted at patients with AS for disease management, formulate a list of app assessment measures from and consistent with evidence-based guidelines to evaluate the features and quality of these apps, and rate app quality using the user version of the Mobile App Rating Scale (uMARS). This will help patients choose a high-quality app for managing their disease and identify gaps in the current apps available for AS management.

\section{Methods}

\section{App Selection}

We conducted a systematic search of all potential apps targeted at patients with AS in November 2020. Android and iOS are the two most popular smartphone operating systems among Chinese smartphone users [30]. The Huawei App Store is one of the biggest Android app stores in China [31]. Thus, we searched for iOS apps in the Apple App Store and Android apps in the Huawei App Store. Preliminary test searches were conducted to determine the search terms before the final search. To ensure all potential apps were screened, our final search terms included ankylosing spondylitis or spondyloarthritis or rheumatic disease or arthritis in both the Huawei and Apple app stores. The final search was conducted following the PRISMA (Preferred Reporting Items for Systematic Reviews and Meta-Analyses) guidelines for systematic reviews. Two reviewers independently downloaded potential apps to test devices for screening according to the inclusion and exclusion criteria. The inclusion criteria for the apps were (1) targeted at patients with AS; (2) in the Chinese language; (3) available for downloading from the Huawei and/or Apple App Stores; (4) able to run on Android and/or iOS operating systems; (4) incorporated at least one of the following elements of disease management and/or patient education: educational information, medication management, exercise management, psychological strategy, symptom management, etc. Apps were excluded if they were not for patient use or not relevant to AS (eg, apps for other chronic conditions or other use). We also excluded apps that had not been updated since 2018. Android apps were downloaded and tested using the Huawei ATH-AL00 with 
Android version 5.1.1, and iOS apps were downloaded and tested using the iPhone 11 with iOS 13.3.1 installed.

\section{App Quality Measures}

We systematically searched guidelines and recommendations for mHealth apps and AS management to identify app quality measures [3,4,32-35]. We formulated a list of quality assessment measures from and consistent with guidelines from the EULAR [4,32-34], the American College of Rheumatology [3], and the French Society for Rheumatology [35]. Then, rheumatologists and rheumatology nurses modified the app quality assessment measures. Finally, the list of app quality measures included two domains: basic characteristics and functionalities. Basic characteristics related to the following features extracted: app name, developer, operating system (iOS or Android), version, provider involvement, star rating (out of 5), number of reviews, number of downloads (only available for Android apps), cost, and privacy policy. Functionalities of the included apps were analyzed as follows: basic information record, educational information, communication, symptom tracking, general or psychological health tracking, medication management, visuals or analysis, exercise management, reminder feature, and information sharing. The app quality measures are shown in Table 1.

Table 1. App quality measures of apps for patients with ankylosing spondylitis.

\begin{tabular}{|c|c|}
\hline Assessment measure & Description and definition \\
\hline \multicolumn{2}{|l|}{ Basic characteristics } \\
\hline App name & App name as shown in the Huawei and/or Apple app stores \\
\hline Developer & Name of the developer (ie, who developed and uploaded the app) \\
\hline Operating system & iOS and/or Android operating systems \\
\hline Version & Latest update version and date of update \\
\hline Provider involvement & $\begin{array}{l}\text { Involvement of relevant health care providers in the design, development, and validation of } \\
\text { the app }\end{array}$ \\
\hline Star rating & Star rating score (out of 5) that users left on the Huawei and/or Apple app stores \\
\hline Number of reviews & Number of reviews that users left on the Huawei and/or Apple app stores \\
\hline Number of downloads & Number of downloads since the app released \\
\hline Cost & Free apps or the cost of apps \\
\hline Privacy policy & Information on how user data are stored and shared \\
\hline \multicolumn{2}{|l|}{ Functionalities } \\
\hline Basic information record & Enables users to record their basic information (eg, gender, age, disease history) \\
\hline Educational information & $\begin{array}{l}\text { The information content is up to date, scientifically justifiable, acceptable to users, and evi- } \\
\text { dence-based. The content includes disease overview, pathogenesis, treatment goal and options, } \\
\text { exercise advice, medication, joint protection, and health advice for daily life }\end{array}$ \\
\hline Communication & Facilitates patient-health care provider communication and patient-patient communication \\
\hline Symptom tracking & $\begin{array}{l}\text { Prompts users to assess their general symptoms as follows: disease activity, pain, fatigue, } \\
\text { morning stiffness, and functional ability }\end{array}$ \\
\hline General or psychological health tracking & $\begin{array}{l}\text { Allows users to record information about their general or psychological health, such as sleep } \\
\text { quality, depression, anxiety, quality of life, and general health }\end{array}$ \\
\hline Medication management & Allows users to record medication name, dosing, time, and frequency \\
\hline Visuals or analysis & Displays recorded information as graphs or tables \\
\hline Exercise management & Allows users to record information pertaining to exercise (eg, frequency, time, type) \\
\hline Reminders & Allows users to set reminders for appointments or when to take their medication \\
\hline Information sharing & $\begin{array}{l}\text { Allows users to share educational information and/or their disease data with health care } \\
\text { providers or others }\end{array}$ \\
\hline
\end{tabular}

\section{App Rating Using the uMARS}

We also used the uMARS to evaluate the quality of apps [36], which is a simplified version of the MARS that has been used to assess the quality of mHealth apps [36,37]. The uMARS is a 20 -item measure that comprises 4 objective quality subscales (engagement, functionality, aesthetics, information quality) and 1 subjective quality subscale [36]. We did not include the latter subscale in this study since our aim was to assess the objective quality of apps. All items were rated on a 5-point Likert scale from 1 (inadequate) to 5 (excellent). Mean scores were calculated for each subscale and a mean total score was calculated across all 4 subscales [36]. Apps that scored $\geq 3$ out of 5 on the uMARS were considered to be of acceptable quality, and scores higher than 4 were rated as high quality [38]. Two trained reviewers independently rated the apps using the 
uMARS. Subsequently, they discussed inconsistencies and doubts about the apps and reached a consensus on the final uMARS scores.

\section{Data Abstraction}

Two reviewers independently downloaded the apps that met the inclusion criteria and evaluated them using our list of quality assessment measures. In addition, they rated the app quality using the uMARS. The main features and quality of all apps were recorded, including basic characteristics, functional features, and uMARS rating.

\section{Results}

\section{App Selection}

Our searches from the Apple App Store retrieved 51 apps. We excluded apps that were duplicates $(n=13)$, not in Chinese $(n=1)$, not relevant to AS (eg, many apps focused on other chronic conditions or provided general health information) $(n=28)$, only for clinician use $(n=3)$, disease activity calculators $(n=1)$, or last updated in $2017(n=1)$. Of the remaining 4 apps, 1 app was not able to run on the iOS operating system and was excluded from the study, leaving 3 apps for the final analysis. A total of 303 Android apps were retrieved from the Huawei App Store. Of these, 299 apps were excluded because they were duplicates $(n=73)$, not relevant to AS (eg, many apps focused on other chronic conditions, or were intended for other use including online shopping, work, and games) $(\mathrm{n}=223)$, only for clinician use $(n=2)$, or could not run on the Android operating system $(n=1)$. Four Android apps were included for analysis. A total of 5 apps were included in the final analysis since 2 apps were available on both the Android and iOS operating systems (Figure 1). Since the 2 apps had the same functionalities on both the iOS and Android operating systems, they were described once. The 5 apps were iRheuma, Wen Wen Feng Shi, Feng Shi Mian Yi Kou Dai Shu, Lei Feng Shi Hu Zhu, and Jian Feng Yuan. iRheuma is an app by the SSDM, which is part of a series of doctor-patient interactive apps developed for the self-management of patients with chronic diseases.

Figure 1. Flow diagram for the systematic search and selection of apps from the Apple and Huawei app stores. AS: ankylosing spondylitis.

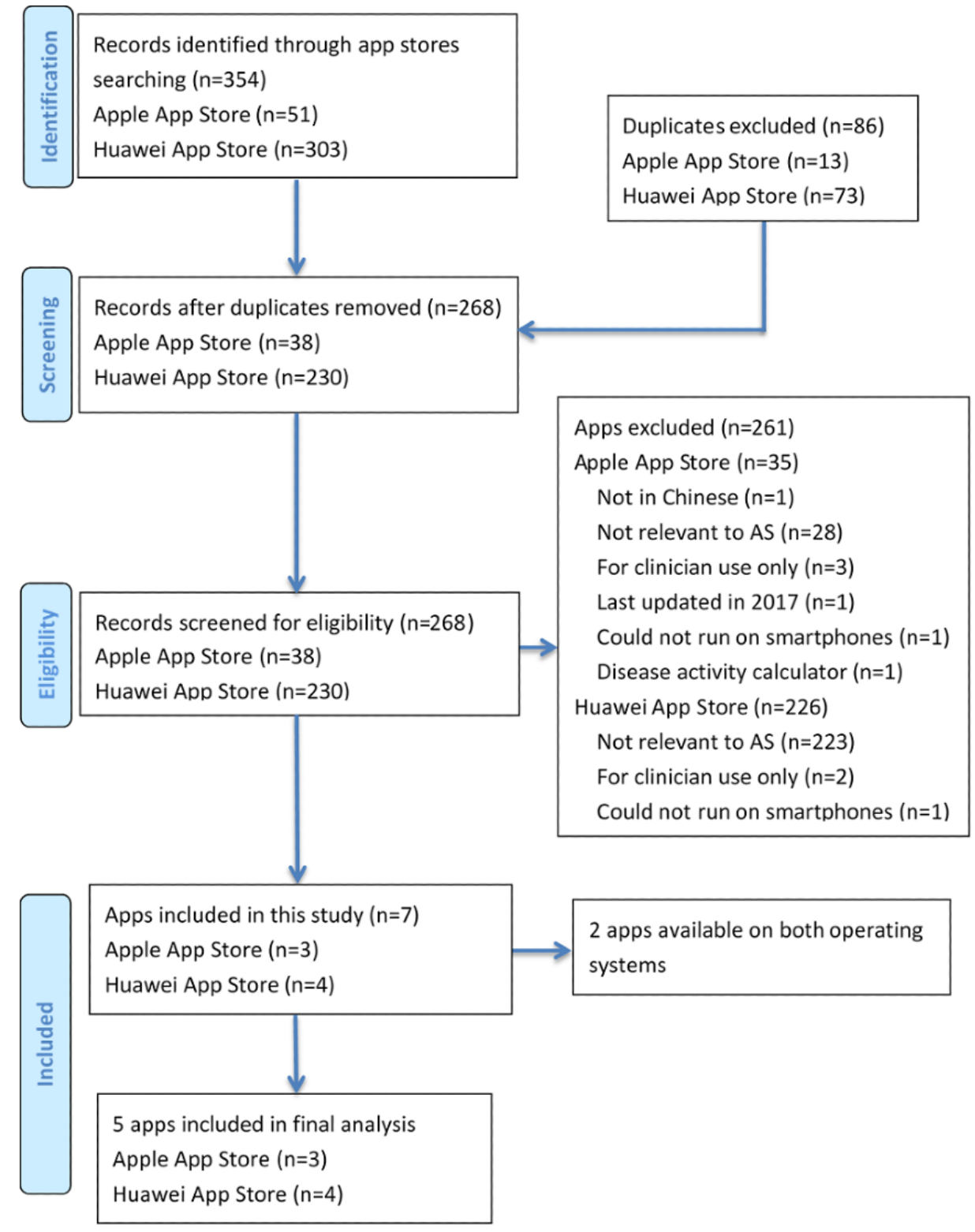




\section{App Characteristics}

The basic characteristics of the app, based on the app quality measures, are summarized in Tables 2 and 3. All apps were specific to people with AS, but some apps were also relevant to other rheumatic diseases, such as rheumatoid arthritis and gout. Two apps $(40 \%)$ were developed by companies, and 2 apps $(40 \%)$ by medical institutions. Four apps $(80 \%)$ were last updated in 2020, and 1 app was updated in 2018. Only 1 app, Feng Shi Mian Yi Kou Dai Shu, described medical professionals involvement in the development of this app. However, we did not know if patients with AS and/or health care providers were involved in the development of the other apps since these apps did not provide information about their design and development. Two app (40\%) received no review, and there was only 1 app (20\%) with more than 10 app store reviews. Of the 4 Android apps with available download data, $3(60 \%)$ were downloaded more than 10,000 times, and $1(20 \%)$ was downloaded 450,000 times. All apps were free for users, and most apps $(n=4,80 \%)$ had a privacy policy.

Table 2. Operating system, developer, version, and health care provider involvement of the included apps.

\begin{tabular}{|c|c|c|c|c|c|c|}
\hline App name & Operating system & Developer & $\begin{array}{l}\text { Date of latest } \\
\text { update }\end{array}$ & iOS version & $\begin{array}{l}\text { Android } \\
\text { version }\end{array}$ & Provider involvement \\
\hline iRheuma & $\begin{array}{l}\text { iOS, } \\
\text { Android }\end{array}$ & $\begin{array}{l}\text { Shanghai Gete Internet } \\
\text { Technology Co, Ltd }\end{array}$ & Dec 2020 & 3.12 .4 & 3.12 .4 & $\mathrm{~N} / \mathrm{A}^{\mathrm{a}}$ \\
\hline Wen Wen Feng Shi & $\begin{array}{l}\text { iOS, } \\
\text { Android }\end{array}$ & $\begin{array}{l}\text { Shanghai Wenyun } \\
\text { Biotechnology Co, Ltd }\end{array}$ & Dec 2020 & 3.2 .4 & 3.2 .3 & N/A \\
\hline $\begin{array}{l}\text { Feng Shi Mian Yi Kou } \\
\text { Dai Shu }\end{array}$ & $\mathrm{iOS}$ & St. Bear Inc & May 2020 & 3.1 & $-^{b}$ & Yes \\
\hline Lei Feng Shi Hu Zhu & Android & $\begin{array}{l}\text { Hu Ze Min Rheumatoid } \\
\text { Hospital of TCM }\end{array}$ & Jul 2020 & - & 3.8 .7 & N/A \\
\hline Jian Feng Yuan & Android & Not stated & Dec 2018 & - & 2.1 & N/A \\
\hline
\end{tabular}

${ }^{\mathrm{a}} \mathrm{N} / \mathrm{A}$ : not applicable.

${ }^{\mathrm{b}}$ Not available.

Table 3. Star rating, number of reviews and downloads, cost, and privacy policy of the included apps.

\begin{tabular}{llllll}
\hline App name & Star rating & Reviews, $\mathrm{n}$ & Downloads, $\mathrm{n}$ & Cost & Privacy policy \\
\hline iRheuma & 4.2 (iOS); 4.3 (Android) & 54 (iOS);10 (Android) & 450,000 & Free & Yes \\
Wen Wen Feng Shi & 4.4 (iOS); 5 (Android) & 28 (iOS); 1 (Android) & 90,000 & Free & Yes \\
$\begin{array}{l}\text { Feng Shi Mian Yi Kou } \\
\text { Dai Shu }\end{array}$ & N/A & 0 & N/A & Free & Yes \\
Lei Feng Shi Hu Zhu & 3.7 & 2 & 20,000 & Free & Yes \\
Jian Feng Yuan & N/A & 0 & $<10,000$ & Free & No \\
\hline
\end{tabular}

${ }^{\mathrm{a}} \mathrm{N} / \mathrm{A}$ : not applicable.

\section{App Functionalities}

The functionalities of the included apps, based on the app quality measures, are shown in Table 4. All apps provided educational information about AS, including disease overview, pathogenesis and cause, symptoms, pharmacological treatment, exercise, and health advice, but none were to tailored individual needs and preferences. Four apps $(80 \%)$ updated their educational information. Of the 5 included apps, only Wen Wen Feng Shi provided educational materials, including the pathogenesis, cause and treatment of AS, health advice on exercise and lifestyle, and updated medical news. 
Table 4. Functionalities of the included apps.

\begin{tabular}{|c|c|c|c|c|c|}
\hline Functionality & iRheuma & Wen Wen Feng Shi & $\begin{array}{l}\text { Feng Shi Mian Yi } \\
\text { Kou Dai Shu }\end{array}$ & $\begin{array}{l}\text { Lei Feng Shi Hu } \\
\text { Zhu }\end{array}$ & Jian Feng Yuan \\
\hline Educational information & $\mathfrak{J}^{\mathrm{a}}$ & $\checkmark$ & $\checkmark$ & $\checkmark$ & $\checkmark$ \\
\hline Basic information record & $\checkmark$ & & $\checkmark$ & $\checkmark$ & \\
\hline Communication & $\checkmark$ & & & & $\checkmark$ \\
\hline Symptom tracking & $\checkmark$ & & & & $\checkmark$ \\
\hline General or psychological health tracking & $\checkmark$ & & & & \\
\hline Medication management & $\checkmark$ & & & & \\
\hline Laboratory result tracking & $\checkmark$ & & & & \\
\hline Visuals or analysis & $\checkmark$ & & & & \\
\hline \multicolumn{6}{|l|}{ Exercise management } \\
\hline Reminders & $\checkmark$ & & & & \\
\hline Information sharing & $\checkmark$ & $\checkmark$ & & $\checkmark$ & \\
\hline
\end{tabular}

${ }^{\mathrm{a}}$ Check mark indicates presence of feature.

Three apps (60\%) allowed users to record their basic information, such as gender, age, health history, and medical record. Two apps (40\%) had a communication feature. iRheuma enabled users to directly consult doctors through text message, telephone call, and video call, but the communication function did not run well because many doctors did not provide online consultation services. Jian Feng Yuan only supported patient-patient communication via a message board.

Symptom tracking was available for 2 apps (40\%): iRheuma and Jian Feng Yuan. iRheuma assessed users' disease activity and functional ability using validated instrument (ie, Ankylosing Spondylitis Disease Activity Score [ASDAS]; Bath Ankylosing Spondylitis Disease Activity Index [BASDAI]; Bath Ankylosing Spondylitis Functional Index [BASFI]). If patients inputted their data, iRheuma could give patients feedback on disease activity and function, and provide individual health advice. Jian Feng Yuan used only the ASDAS to assess users' disease activity and calculated an ASDAS score.

iRheuma also provided general or psychological health tracking, medication management, laboratory result tracking, visuals or analysis, and reminders. iRheuma used validated instruments (Hospital Anxiety and Depression Scale, Pittsburgh Sleep Quality Index, Medical Outcomes Study Short Form 36-item Health Survey) to assess patients' health and to give them feedback and tailored health advice. iRheuma enabled users to record their medication and laboratory results, and to set reminders to take their medication. This app could create graphs from user-reported data to track users' symptoms and laboratory results.

No app had an exercise management feature. Three apps (60\%) supported an information-sharing function, but they only allowed users to share health information with other people via WeChat, Tencent QQ, and email. Some functions of the included apps did not run well due to technical issues. Among these apps, iRheuma was downloaded 450,000 times more than other apps.

\section{Additional Functionalities}

Two apps (40\%) supported online shopping. Users could purchase medications, medical devices, and medical books on these apps. One app provided questions about the Modified New York Classification Criteria for AS [39] to screen for AS. Two apps (40\%) enabled users to make appointments with doctors. Most apps $(4 / 5,80 \%)$ linked to a WeChat public account with content and functions similar that in the app.

\section{App Rating Based on the uMARS}

Table 5 shows the uMARS ratings for all included apps. The overall uMARS scores for the apps ranged from 2.7 to 4.2 . Three (60\%) apps scored more than 3 out of 5; only iRheuma (4.2) app scored than 4 out of 5 . Information quality scores (2.8-4.5) showed the greatest variability. The engagement scores (2.2-3.8) were the lowest of the 4 subscales. 
Table 5. The user version of the Mobile App Rating Scale (uMARS) scores of the included apps.

\begin{tabular}{|c|c|c|c|c|c|}
\hline \multirow[t]{2}{*}{ App name } & \multicolumn{4}{|c|}{ uMARS subscale score } & \multirow[t]{2}{*}{ Overall score } \\
\hline & Engagement & Functionality & Aesthetics & Information quality & \\
\hline \multicolumn{6}{|l|}{ iRheuma } \\
\hline iOS & 3.8 & 4.3 & 4.3 & 4.5 & 4.2 \\
\hline Android & 3.8 & 4.3 & 4.3 & 4.5 & 4.2 \\
\hline \multicolumn{6}{|c|}{ Wen Wen Feng Shi } \\
\hline iOS & 2.6 & 3.5 & 3.7 & 3.5 & 3.3 \\
\hline Android & 2.6 & 3.5 & 3.7 & 3.5 & 3.3 \\
\hline \multicolumn{6}{|c|}{ Feng Shi Mian Yi Kou Dai Shu } \\
\hline iOS & 2.4 & 3.3 & 3.0 & 2.8 & 2.9 \\
\hline \multicolumn{6}{|c|}{ Lei Feng Shi Hu Zhu } \\
\hline Android & 2.2 & 3.0 & 2.7 & 2.8 & 2.7 \\
\hline \multicolumn{6}{|c|}{ Jian Feng Yuan } \\
\hline Android & 2.8 & 3.0 & 3.7 & 3.3 & 3.2 \\
\hline
\end{tabular}

\section{Discussion}

\section{Principal Findings}

This study utilized a systematic approach to identify and evaluate 5 mHealth apps for AS management in China. We found only 1 app (with an overall uMARS score of 4.2) that provided comprehensive functions that adhered to evidence-based guidelines for AS management. This result was line with previous reviews of apps on gout and rheumatoid arthritis [20,40]. Most apps in the study did not provide further information regarding the development process of the apps. Similarly, Najm et al [18] also found that the development process of most apps were not sufficient or were not described in the existing literature, which might raise questions about apps' credibility. Thus, international guidelines and regulations for the design, development, and validation of mHealth apps are needed in the future. Additionally, our results were in line with previous evidence that most apps designed for patient use did not involve health care providers or patients in the development stage [18]. Prior evidence suggested that the development and validation of self-management apps should involve target users and health care providers [32,41].

The EULAR has recommended that mHealth apps should be relevant and tailored to the individual needs of people with rheumatic and musculoskeletal disease [32,34]. In our study, educational information in most of the apps was not tailored to patients' needs and preferences. It may be that patients and health care professionals were not involved in the development of the apps [18]. Moreover, the educational information in some apps was not divided into different disease modules, which may make it difficult for users to find information on AS. We did not systematically evaluate patient acceptability of these apps due to lack of a quantitative assessment. Future mobile apps should provide evidence-based educational information and increase apps' usability based on patients' needs and health care professionals' perspectives.
Many symptom-tracking apps for rheumatic disease did not use validated instruments [16,29]; only 2 apps in this study used validated instruments to track patients' symptoms. iRheuma used the ASDAS, BASDAI, and BASFI to track users' disease activity and functional ability. Moreover, iRheuma was also able to provide feedback on users' conditions and encourage users to consult with doctors, which may enable users to better understand their conditions and monitor their disease. Another app, Jian Feng Yuan, could calculate users' disease activity (using the ASDAS). Both apps lacked the ability to directly transmit data to health care providers. Although evidence has suggested that mobile apps that use a validated instrument and have a tracking function may be useful for patients with arthritis for symptom monitoring [16,29], most of these apps, as well as the ones from our study, were not assessed in clinical trials. Thus, future studies should explore the effects of these apps on health and economic outcomes.

In this study, 1 app had a reminder feature. Prior work has suggested that apps with such a function may be effective in improving medication adherence in nonadherent patients [42]. It is important to integrate this function into clinical practice. However, the feasibility and effects of reminder apps have not been well studied. Future studies should explore the efficacy of reminder apps in large populations.

Of the included 5 apps, only iRheuma provided comprehensive functions, including direct communication, health tracking, medication management, and laboratory results tracking. These functions may help patients better manage their conditions. Additionally, we found that iRheuma was the most frequently downloaded app of the 5 apps, indicating that multifunction apps may be attractive for patients with AS. Luo et al [20] revealed that only $25 \%$ of reviewed apps provided symptom tracking and education for patients about management strategies [20]. Although international guidelines have revealed the importance of exercise for AS management $[3,43,44]$, none of the apps provided this function. Future studies should develop comprehensive, evidence-based apps for patients with AS. 
The overall uMARS scores ranged from 2.7 to 4.2 , indicating inconsistent quality among the included apps. This result is similar to previous studies reviewing mHealth apps $[29,45]$. Only 1 app (iRheuma) provided comprehensive functions for AS management and was considered high quality based on the uMARS. The 2 highest scoring apps, iRheuma (4.2) and Wen Wen Feng Shi (3.3), were most frequently downloaded, indicating that the high-quality apps may be useful for targeted users. Engagement scores were lower compared to the other 3 subscales, and nearly half $(2 / 5,40 \%)$ of the apps were considered to be of poor quality. Thus, future studies and practice should improve apps' quality for AS management, especially engagement quality.

\section{Strengths and Limitations}

Strengths of this study included the assessment of a broad range of app characteristics, including basic characteristics, functionalities, and app ratings using uMARS scores. This study also had several limitations. One limitation is that we only focused on Chinese-language apps available on the two most popular operating systems (Android and iOS), and thus missed apps available in other languages or on other operating systems. Although WeChat public accounts have been increasingly used as mHealth tools in China [46], we did not include WeChat public accounts for AS management, such as the Smart-phone SpondyloArthritis Management System [11]. We searched for apps in two of the most popular app stores (the Huawei and Apple App Stores) for Android and iOS operating systems in
China, but apps exclusively in other app stores (eg, Microsoft) were not included in this study. This study also only focused on publicly available apps. Apps available in the published literature were not included since limited published works have focused on apps for AS management. The uMARS does not focus on AS management apps. Thus, we developed a list of app quality assessment measures based on evidence-based guidelines and recommendations for mHealth apps and AS management. The app quality measures have not been validated, which may limit the findings of this study.

\section{Conclusions}

This study found a lack in high-quality apps available to assist in the management of AS in China. Only 1 out of the 5 apps was of high quality and provided comprehensive functions to help patients manage their conditions. Most apps lacked key features for disease management, such as symptom tracking, medication management, and reminders. This study only assessed the app quality and did not evaluate the usability and efficacy of the included apps. Future studies and clinical practice should explore the efficacy and feasibility of mHealth apps. International guidelines and regulations for the design, development, validation, and implementation of mHealth apps are also needed in the future. In the meantime, health care providers, patients with AS, and app developers should collaborate to develop high-quality, evidence-based apps that consider patients' needs and health care professionals' perspectives.

\section{Acknowledgments}

The authors thank Ms Yao Yin for her valuable input, as well as the academic editor, peer reviewers, and copyeditor, who supported this study. The authors also thank their research assistants for their assistance.

\section{Conflicts of Interest}

None declared.

\section{References}

1. Braun J, Sieper J. Ankylosing spondylitis. Lancet 2007 Apr 21;369(9570):1379-1390. [doi: 10.1016/S0140-6736(07)60635-7] [Medline: 17448825$]$

2. Kotsis K, Voulgari PV, Drosos AA, Carvalho AF, Hyphantis T. Health-related quality of life in patients with ankylosing spondylitis: a comprehensive review. Expert Rev Pharmacoecon Outcomes Res 2014 Dec;14(6):857-872. [doi: 10.1586/14737167.2014.957679] [Medline: $\underline{25193010]}$

3. Ward MM, Deodhar A, Gensler LS, Dubreuil M, Yu D, Khan MA, et al. 2019 Update of the American College of Rheumatology/Spondylitis Association of America/Spondyloarthritis Research and Treatment Network Recommendations for the Treatment of Ankylosing Spondylitis and Nonradiographic Axial Spondyloarthritis. Arthritis Rheumatol 2019 Oct;71(10):1599-1613. [doi: 10.1002/art.41042] [Medline: 31436036]

4. van der Heijde D, Ramiro S, Landewé R, Baraliakos X, Van den Bosch F, Sepriano A, et al. 2016 update of the ASAS-EULAR management recommendations for axial spondyloarthritis. Ann Rheum Dis 2017 Jun;76(6):978-991. [doi: 10.1136/annrheumdis-2016-210770] [Medline: 28087505]

5. Whitehead L, Seaton P. The Effectiveness of Self-Management Mobile Phone and Tablet Apps in Long-term Condition Management: A Systematic Review. J Med Internet Res 2016 May 16;18(5):e97 [FREE Full text] [doi: 10.2196/jmir.4883] [Medline: 27185295]

6. Liu Y, Yang H. The value of chronic disease management on rheumatic disease. Medical Journal of West China 2019;31(11):1641-1642, 1645. [doi: 10.3969/J.issn.1672-3511.2019.11.001]

7. Zhou Y, Liu M, Pan X, Xie C, Li Z. Clinical Significance of Mobile Medical Model in Diagnosis and Treatment of Ankylosing Spondylitis. Rheumatism and Arthritis 2019 Mar;8(3):28-32. [doi: 10.3969/j.issn.2095-4174.2019.03.005]

8. Muellmann S, Bragina I, Voelcker-Rehage C, Rost E, Lippke S, Meyer J, et al. Development and evaluation of two web-based interventions for the promotion of physical activity in older adults: study protocol for a community-based controlled 
intervention trial. BMC Public Health 2017 May 25;17(1):512 [FREE Full text] [doi: 10.1186/s12889-017-4446-x] [Medline: 28545506]

9. Srikesavan C, Bryer C, Ali U, Williamson E. Web-based rehabilitation interventions for people with rheumatoid arthritis: A systematic review. J Telemed Telecare 2019 Jun;25(5):263-275. [doi: 10.1177/1357633x18768400] [Medline: 29669470]

10. Ji X, Hu L, Wang Y, Luo Y, Zhu J, Zhang J, et al. "Mobile Health" for the Management of Spondyloarthritis and Its Application in China. Curr Rheumatol Rep 2019 Nov 19;21(11):61. [doi: 10.1007/s11926-019-0860-7] [Medline: 31741083 ]

11. Ji X, Wang Y, Ma Y, Hu Z, Man S, Zhang Y, et al. Improvement of Disease Management and Cost Effectiveness in Chinese Patients with Ankylosing Spondylitis Using a Smart-Phone Management System: A Prospective Cohort Study. Biomed Res Int 2019 Feb 25;2019:2171475. [doi: 10.1155/2019/2171475] [Medline: 30931322]

12. Zhang F. Second Survey of Chinese Rheumatologists. Chin J Allergy Clin Immunol 2014;8(3):165-169. [doi: 10.3969/j.issn.1673-8705.2014.03.001]

13. Lv Q, Jiang Y, Qi J, Zhang Y, Zhang X, Fang L, et al. Using Mobile Apps for Health Management: A New Health Care Mode in China. JMIR Mhealth Uhealth 2019 Jun 03;7(6):e10299 [FREE Full text] [doi: 10.2196/10299] [Medline: 31162131]

14. Azevedo AR, de Sousa HM, Monteiro JA, Lima AR. Future perspectives of Smartphone applications for rheumatic diseases self-management. Rheumatol Int 2014 Aug 29;35(3):419-431. [doi: 10.1007/s00296-014-3117-9] [Medline: 25168866]

15. Tian M, Zhang J, Luo R, Chen S, Petrovic D, Redfern J, et al. mHealth Interventions for Health System Strengthening in China: A Systematic Review. JMIR Mhealth Uhealth 2017 Mar 16;5(3):e32 [FREE Full text] [doi: 10.2196/mhealth.6889] [Medline: 28302597]

16. Grainger R, Townsley H, White B, Langlotz T, Taylor WJ. Apps for People With Rheumatoid Arthritis to Monitor Their Disease Activity: A Review of Apps for Best Practice and Quality. JMIR Mhealth Uhealth 2017 Feb 21;5(2):e7 [FREE Full text] [doi: 10.2196/mhealth.6956] [Medline: 28223263]

17. WHO Global Observatory for eHealth. mHealth: new horizons for health through mobile technologies: Second global survey on eHealth. World Health Organization. 2011. URL: https://apps.who.int/iris/handle/10665/44607 [accessed 2020-12-01]

18. Najm A, Gossec L, Weill C, Benoist D, Berenbaum F, Nikiphorou E. Mobile Health Apps for Self-Management of Rheumatic and Musculoskeletal Diseases: Systematic Literature Review. JMIR Mhealth Uhealth 2019 Nov 26;7(11):e14730 [FREE Full text] [doi: 10.2196/14730] [Medline: 31769758]

19. Huckvale K, Car M, Morrison C, Car J. Apps for asthma self-management: a systematic assessment of content and tools. BMC Med 2012 Nov 22;10:144 [FREE Full text] [doi: 10.1186/1741-7015-10-144] [Medline: 23171675]

20. Luo D, Wang P, Lu F, Elias J, Sparks JA, Lee YC. Mobile Apps for Individuals With Rheumatoid Arthritis: A Systematic Review. J Clin Rheumatol 2019 Apr;25(3):133-141. [doi: 10.1097/RHU.0000000000000800] [Medline: 29933327]

21. Con D, De Cruz P. Mobile Phone Apps for Inflammatory Bowel Disease Self-Management: A Systematic Assessment of Content and Tools. JMIR Mhealth Uhealth 2016 Feb 01;4(1):e13 [FREE Full text] [doi: 10.2196/mhealth.4874] [Medline: 26831935]

22. Beratarrechea A, Lee AG, Willner JM, Jahangir E, Ciapponi A, Rubinstein A. The impact of mobile health interventions on chronic disease outcomes in developing countries: a systematic review. Telemed J E Health 2014 Jan;20(1):75-82 [FREE Full text] [doi: 10.1089/tmj.2012.0328] [Medline: 24205809]

23. The 46th China statistical report on internet development. China Internet Network Information Center. 2020 Sep 29. URL: http://www.cnnic.cn/gywm/xwzx/rdxw/202009/W020200929343125745019.pdf [accessed 2020-12-02]

24. Mollard E, Michaud K. Mobile Apps for Rheumatoid Arthritis: Opportunities and Challenges. Rheum Dis Clin North Am 2019 May;45(2):197-209. [doi: 10.1016/j.rdc.2019.01.011] [Medline: 30952393]

25. Cooksey R, Brophy S, Husain MJ, Irvine E, Davies H, Siebert S. The information needs of people living with ankylosing spondylitis: a questionnaire survey. BMC Musculoskelet Disord 2012 Dec 10;13:243. [doi: 10.1186/1471-2474-13-243] [Medline: 23227937]

26. Haglund E, Bremander A, Bergman S, Larsson I. Educational needs in patients with spondyloarthritis in Sweden - a mixed-methods study. BMC Musculoskelet Disord 2017 Aug 2;18(1):335. [doi: 10.1186/s12891-017-1689-8] [Medline: $\underline{28768510}]$

27. Xiao F, Liu X, Wei H, Zhou H, Wang H, Jiang Y, et al. AB1001 Online Consultation for Chinese Patients with Rheumatic Diseases Based on Smart System of Disease Management (SSDM) Mobile Tools: A Study of Medical Economics. Ann Rheum Dis 2016 Jul 15;75(Suppl 2):1243-1244. [doi: 10.1136/annrheumdis-2016-eular.3933]

28. Nicholas J, Larsen ME, Proudfoot J, Christensen H. Mobile Apps for Bipolar Disorder: A Systematic Review of Features and Content Quality. J Med Internet Res 2015 Aug 17;17(8):e198 [FREE Full text] [doi: 10.2196/jmir.4581] [Medline: $\underline{26283290]}$

29. Kwan YH, Ong WJ, Xiong M, Leung YY, Phang JK, Wang CTM, et al. Evaluation of Mobile Apps Targeted at Patients With Spondyloarthritis for Disease Monitoring: Systematic App Search. JMIR Mhealth Uhealth 2019 Oct 28;7(10):e14753 [FREE Full text] [doi: 10.2196/14753] [Medline: $\underline{\text { 31661080] }}$

30. Statista Research Department. Market share of mobile operating systems in China from January 2013 to May 2020. Statista. 2020. URL: https://www.statista.com/statistics/262176/market-share-held-by-mobile-operating-systems-in-china/ [accessed 2021-03-01] 
31. 2018-2019 China Mobile App Store Market Annual Monitoring Report. iiMedia. 2018. URL: https://www.iimedia.cn/c400/ 63240.html [accessed 2021-02-28]

32. Najm A, Nikiphorou E, Kostine M, Richez C, Pauling JD, Finckh A, et al. EULAR points to consider for the development, evaluation and implementation of mobile health applications aiding self-management in people living with rheumatic and musculoskeletal diseases. RMD Open 2019 Sep 13;5(2):e001014. [doi: 10.1136/rmdopen-2019-001014] [Medline: 31565245]

33. Harvard S, Gossec L, Pham T, Richette P, Dougados M, Anis A, et al. Measurable definitions of ankylosing spondylitis management recommendations are needed for use in observational studies. Joint Bone Spine 2016 Jan;83(1):101-103. [doi: 10.1016/j.jbspin.2015.01.019] [Medline: 25776447]

34. Zangi HA, Ndosi M, Adams J, Andersen L, Bode C, Boström C, European League Against Rheumatism (EULAR). EULAR recommendations for patient education for people with inflammatory arthritis. Ann Rheum Dis 2015 Jun;74(6):954-962. [doi: 10.1136/annrheumdis-2014-206807] [Medline: 25735643]

35. Wendling D, Lukas C, Prati C, Claudepierre P, Gossec L, Goupille P, et al. 2018 update of French Society for Rheumatology (SFR) recommendations about the everyday management of patients with spondyloarthritis. Joint Bone Spine 2018 May;85(3):275-284. [doi: 10.1016/j.jbspin.2018.01.006] [Medline: 29407043]

36. Stoyanov SR, Hides L, Kavanagh DJ, Wilson H. Development and Validation of the User Version of the Mobile Application Rating Scale (uMARS). JMIR Mhealth Uhealth 2016 Jun 10;4(2):e72 [FREE Full text] [doi: 10.2196/mhealth.5849] [Medline: 27287964]

37. Stoyanov SR, Hides L, Kavanagh DJ, Zelenko O, Tjondronegoro D, Mani M. Mobile app rating scale: a new tool for assessing the quality of health mobile apps. JMIR Mhealth Uhealth 2015 Mar 11;3(1):e27 [FREE Full text] [doi: 10.2196/mhealth.3422] [Medline: 25760773]

38. Stec MA, Arbour MW, Hines HF. Client - Centered Mobile Health Care Applications: Using the Mobile Application Rating Scale Instrument for Evidence - Based Evaluation. J Midwifery Womens Health 2019 May;64(3):324-329. [doi: 10.1111/jmwh.12941] [Medline: $\underline{30887711]}$

39. van der Linden S, Valkenburg HA, Cats A. Evaluation of diagnostic criteria for ankylosing spondylitis. A proposal for modification of the New York criteria. Arthritis Rheum 1984 Apr;27(4):361-368. [doi: 10.1002/art.1780270401] [Medline: $\underline{6231933}]$

40. Nguyen AD, Baysari MT, Kannangara DR, Tariq A, Lau AY, Westbrook JI, et al. Mobile applications to enhance self-management of gout. Int J Med Inform 2016 Oct;94:67-74. [doi: 10.1016/j.ijmedinf.2016.06.021] [Medline: 27573313]

41. Llorens-Vernet P, Miró J. Standards for Mobile Health-Related Apps: Systematic Review and Development of a Guide. JMIR Mhealth Uhealth 2020 Mar 03;8(3):e13057 [FREE Full text] [doi: 10.2196/13057] [Medline: $\underline{\text { 32130169] }}$

42. Dayer L, Heldenbrand S, Anderson P, Gubbins PO, Martin BC. Smartphone medication adherence apps: Potential benefits to patients and providers. J Am Pharm Assoc (2003) 2013;53(2):172-181. [doi: 10.1331/JAPhA.2013.12202] [Medline: 23571625]

43. Ozgocmen S, Akgul O, Altay Z, Altindag O, Baysal O, Calis M, Anatolian Group for the Assessment in Rheumatic Diseases. Expert opinion and key recommendations for the physical therapy and rehabilitation of patients with ankylosing spondylitis. Int J Rheum Dis 2012 Jun;15(3):229-238. [doi: 10.1111/j.1756-185x.2011.01700.x] [Medline: 22709485]

44. Millner JR, Barron JS, Beinke KM, Butterworth RH, Chasle BE, Dutton LJ, et al. Exercise for ankylosing spondylitis: An evidence-based consensus statement. Semin Arthritis Rheum 2016 Feb;45(4):411-427. [doi: 10.1016/j.semarthrit.2015.08.003] [Medline: 26493464]

45. Li Y, Ding J, Wang Y, Tang C, Zhang P. Nutrition-Related Mobile Apps in the China App Store: Assessment of Functionality and Quality. JMIR Mhealth Uhealth 2019 Jul 30;7(7):e13261 [FREE Full text] [doi: 10.2196/13261] [Medline: 31364606$]$

46. Wang F, Wang Z, Sun W, Yang X, Bian Z, Shen L, et al. Evaluating the Quality of Health-Related WeChat Public Accounts: Cross-Sectional Study. JMIR Mhealth Uhealth 2020 May 08;8(5):e14826 [FREE Full text] [doi: 10.2196/14826] [Medline: 32383684]

\section{Abbreviations}

AS: ankylosing spondylitis

ASDAS: Ankylosing Spondylitis Disease Activity Score

BASDAI: Bath Ankylosing Spondylitis Disease Activity Index

BASFI: Bath Ankylosing Spondylitis Functional Index

EULAR: European League Against Rheumatism

MARS: Mobile App Rating Scale

mHealth: mobile health

PRISMA: Preferred Reporting Items for Systematic Reviews and Meta-Analyses

SSDM: Smart System of Disease Management

uMARS: Mobile App Rating Scale, user version 
Edited by L Buis; submitted 18.01.21; peer-reviewed by F Huang, KL Mauco, B Nievas Soriano; comments to author 22.02.21; revised version received 01.04.21; accepted 27.05.21; published 14.07.21

Please cite as:

Song $Y$, Chen $H$

Evaluating Chinese Mobile Health Apps for Ankylosing Spondylitis Management: Systematic App Search

JMIR Mhealth Uhealth 2021;9(7):e27234

URL: https://mhealth.jmir.org/2021/7/e27234

doi: $10.2196 / 27234$

PMID: $\underline{34259644}$

(C) Yuqing Song, Hong Chen. Originally published in JMIR mHealth and uHealth (https://mhealth.jmir.org), 14.07.2021. This is an open-access article distributed under the terms of the Creative Commons Attribution License (https://creativecommons.org/licenses/by/4.0/), which permits unrestricted use, distribution, and reproduction in any medium, provided the original work, first published in JMIR mHealth and uHealth, is properly cited. The complete bibliographic information, a link to the original publication on https://mhealth.jmir.org/, as well as this copyright and license information must be included. 